\title{
Involvement of RHO GTPases and ERK in synuclein- $\gamma$ enhanced cancer cell motility
}

\author{
ZHONG-ZONG PAN ${ }^{1,2}$, WENDY BRUENING ${ }^{2,3}$ and ANDREW K. GODWIN ${ }^{2}$ \\ ${ }^{1}$ Department of Animal Science, University of Vermont, 570 Main Street, Burlington, VT 05405; \\ ${ }^{2}$ Department of Medical Oncology, Fox Chase Cancer Center, 333 Cottman Avenue, Philadelphia, PA 19111, USA
}

Received May 8, 2006; Accepted July 7, 2006

\begin{abstract}
Synuclein- $\gamma$ is aberrantly expressed in more than $70 \%$ of stage III/IV breast and ovarian carcinomas. Ectopic overexpression of synuclein- $\gamma$ enhanced MDA-MB-435 cell migration in vitro and metastasis in a nude mouse model. However, the mechanism of how synuclein- $\gamma$ promotes cell motility is not clear. In our previous studies, we showed that synuclein $-\gamma$ overexpression activates ERK. In the present study, we overexpressed synuclein- $\gamma$ in several breast and ovarian cancer cell lines and evaluated the effect of synuclein- $\gamma$ on the activity of small G-protein RHO family members. We found that at least one of the RHO/RAC/CDC42 GTPases showed a higher level of the GTP-bound active form. Consistent with their role in regulating the intracellular motile machinery, inhibition of the RHO/RAC/CDC42 by $C$. difficile Toxin B blocked cell migration in both parental cells and synuclein- $\gamma$ overexpressing cells. The ERK inhibitor U0126 also blocked the cell migration in both parental cells and synuclein- $\gamma$ overexpressing cells. Collectively, our data indicate that synuclein- $\gamma$ might be involved in late stage breast and ovarian cancer metastasis by enhancing cell motility through activation of the RHO family small-GTPases and ERK.
\end{abstract}

\section{Introduction}

The synucleins (synucleins- $\alpha,-\beta,-\gamma$, and synoretin) are a family of small, highly soluble proteins that are normally expressed predominantly in neurons $(1,2)$. Although the expression patterns and abundance of the synucleins suggest their importance in neuron development and function, very little is known about their physiological functions. Among

Correspondence to: Dr Zhongzong Pan, Department of Animal Science, University of Vermont, 570 Main Street, Burlington, VT 05405, USA

E-mail: zpan@uvm.edu

Present address: ${ }^{3}$ Health Technology Assessment Information Service, Plymouth Meeting, PA 19462, USA

Key words: synuclein- $\gamma$, cell motility, RHO, GTPase, ERK, breast cancer, ovarian cancer the synuclein proteins, synuclein- $\alpha$ is associated with neurodegenerative diseases such as Parkinson's disease and Alzheimer's disease $(1,3)$. Synuclein- $\gamma$, also referred to as breast cancer specific gene 1 (BCSG1), has been identified to be aberrantly up-regulated in breast and ovarian cancers $(4,5)$. Abnormal expression of synuclein- $\gamma$ has also been identified in several other cancer types including bladder and colorectal carcinomas, glaucoma, and brain tumor (6-10). The abnormal expression of synuclein- $\gamma$ in cancer cells is caused by the loss of epigenetic control as a result of hypomethylation of the $\mathrm{CpG}$ island in the synuclein- $\gamma$ gene (11).

The expression of synuclein- $\gamma$ in primary breast and ovarian cancers is strongly associated with advanced stages of tumor progression. Synuclein- $\gamma$ is not expressed in normal or benign breast and ovarian tissues, but is highly expressed in the vast majority $(>70 \%)$ of stage III/IV breast and ovarian tumors $(4,5)$. Several lines of evidence suggest that synuclein- $\gamma$ might be a malignant factor. In our previous studies, we found that synuclein- $\gamma$ can promote cell survival and inhibit stress- and microtubule inhibitory drug-induced apoptosis by modulating JNK and ERK pathways (12). In breast cancer cells, synuclein $-\gamma$ can activate estrogen receptor (ER), promote cell proliferation, and inhibit mitotic checkpoint control (13-18). In breast cancer cell line MDA-MB-435 cells, ectopic overexpression of synuclein- $\gamma$ enhanced cell migration in vitro as well as metastasis in a nude mouse model (19). The mechanism of how synuclein- $\gamma$ promotes cell motility is not clear. Upregulation of matrix metalloproteinases- 2 and -9 (MMPs) by synuclein- $\gamma$ has been found in retinoblastoma Y79 cells, but MMP-2 and MMP-9 were not found activated in MDA-435 cells that overexpress synuclein- $\gamma(19,20)$.

Cell migration and invasion involves dynamic changes in extracellular matrix, cell surface structures including focal adhesions, interaction with neighboring cells, and the intracellular motile machinery including actin stress fiber and myosin reorganization (21-23). The small GTPases of the RHO family have been shown to play pivotal roles in these signal transduction pathways leading to cell migration and metastasis (24-26). In addition to RHO family members, several other signaling pathways have been identified to promote cell migration and invasion. Such pathways include ERK, CAS/CRK, PI3K-AKT pathway, and the low M(r) protein-tyrosine phosphatase (PTP) (27-34). In the present study, we overexpressed synuclein- $\gamma$ in breast MDA-435 cells 
and ovarian A2780 and OVCAR5 cells and evaluated its effect on the activity of the RHO family members. Our data indicate that both RHO and ERK are involved in synuclein- $\gamma$ enhanced cell migration.

\section{Materials and methods}

Cell culture. Ovarian cancer cell lines A2780 and OVCAR5 were maintained in 10\% FBS DMEM and 10\% FBS RPMI1640 , respectively. Breast cancer cell line MDA-MB-435 (kindly provided by J.W. Liu) was maintained in 10\% FBS DMEM/F12. Synuclein- $\gamma$ overexpressing cells were derived by transfection and neomycin selection following the procedure as previously described (12). To knock-down synuclein- $\gamma$, OVCAR5 cells were transfected with siRNA duplex (Dharmacon Res. Inc.) and oligofectamine (Invitrogen) following the manufacturer's protocols. The sequences of duplex siRNA specific for $\gamma$-synuclein are as follows: 5'- GGA GAAUGUUGUACAGAGCUU-3' (sense strand), and 3'UUCCUCUUACAACAUGUCUCG-5' (antisense strand). Synuclein $-\gamma$ protein level can be dramatically suppressed after two-round transfection.

Assays for cell migration and invasion. Boyden chamber assay was used for cell migration and invasion assay. Cells $\left(3 \times 10^{5}\right)$ were placed into the upper chamber of Biocoat cell culture chambers ( $8-\mu \mathrm{m}$ pore size) (Becton Dickinson, Bedford, MA). FBS medium (10\%) was added to both upper and lower chambers. To evaluate the numbers of cells undergoing migration and invasion, cells on the surface of the upper chamber were removed by swiping with cotton swabs. After fixing and staining with Protocol Hema3 Staining Set (Biochemical Sci. Inc., Swedesboro, NJ), the cells on the surface of the bottom chamber were counted at magnification 10x10. The number of migration cells per field (at magnification 10x10) was the average of five independent fields counted for each chamber. Where indicated, a two-tailed Student's t-test was used to test for significance.

RHO/RAC/CDC42 activity assay. Cells at $70-80 \%$ confluence were washed twice with ice-cold DPBS before scraping with lysis buffer (Upstate, Lake Placid, NY) on ice. For RAC/CDC42 assay, the cells were lysed in 1X MLB (25 mM HEPES, pH 7.5, $150 \mathrm{mM} \mathrm{NaCl}, 1 \%$ lgepal CA-630, $10 \mathrm{mM}$ $\mathrm{MgCl}_{2}, 1 \mathrm{mM}$ EDTA, and $10 \%$ glycerol, $5 \mathrm{mM} \mathrm{NaF}, 1 \mathrm{mM}$ $\mathrm{Na}_{3} \mathrm{VO}_{4}$ ) containing protease inhibitor cocktail (Roche, Indianapolis, IN). For RHO assay, cells were lysed in 1X RLB (50 mM Tris- $\mathrm{HCl}, \mathrm{pH} 7.2 ; 500 \mathrm{mM} \mathrm{NaCl} ; 10 \mathrm{mM} \mathrm{MgCl}_{2}$, $0.5 \%$ sodium deoxycholate, $0.1 \% \mathrm{SDS}, 5 \mathrm{mM} \mathrm{NaF}, 1 \mathrm{mM}$ $\mathrm{Na}_{3} \mathrm{VO}_{4}, 1 \mathrm{mM}$ PMSF, $1 \%$ Triton X-100) with the protease inhibitor cocktail. Cellular debris was removed by centrifugation at $14,000 \mathrm{x} \mathrm{g}$ for $15 \mathrm{~min}$ at $4^{\circ} \mathrm{C}$. Protein concentrations were determined using Bio-Rad DC protein assay reagents, and total cell lysate $(1000 \mu \mathrm{g}$ protein in $1 \mathrm{ml})$ was immunoprecipitated with either $10 \mu \mathrm{g}$ PAK-1 PBD agarose (for RAC and $\mathrm{CDC} 42$ ) or $30 \mu \mathrm{g}$ Rhotekin RBD agarose (for RHO) at $4^{\circ} \mathrm{C}$ for $1 \mathrm{~h}$. After washing 3 times with lysis buffer, the pull-out GTP-bound $\mathrm{RHO} / \mathrm{RAC} / \mathrm{CDC} 42$ protein was eluted by boiling in SDS-sample buffer and evaluated by SDS-PAGE and immuno-blotting.
SDS-PAGE and immuno-blotting. For SDS-PAGE, proteins in the total cell lysate or eluted from agarose beads were separated on 4-20\% linear gradient Tris- $\mathrm{HCl}$ ready gels (Bio-Rad), and transferred onto PVDF membranes (Millipore, Bedford, MA). Anti-ERK1 and anti-ERK2 antibodies were obtained from Santa Cruz Biotechnology, Inc. (Santa Cruz, CA). Anti-phospho-ERK1/2 was obtained from Cell Signaling Technology (Beverly, MA). $\gamma-2$ (gift from Dr B.I. Giasson) is a rabbit polyclonal antibody against synuclein $-\gamma$. The results of immuno-blotting were quantitated using the NIH Image for the integrated density of each band.

\section{Results}

Synuclein- $\gamma$ overexpression enhanced cell migration in breast and ovarian cancer cells. The close correlation of synuclein- $\gamma$ expression and breast and ovarian cancer staging suggests that synuclein- $\gamma$ might be involved in advanced stage tumor progression and metastasis. Jia and colleagues showed that synuclein- $\gamma$ overexpression in breast cancer cell line MDAMB-435 cells enhanced cell motility in vitro and metastasis in vivo (19). To unravel the molecular mechanism by which synuclein- $\gamma$ promotes cell motility, we overexpressed synuclein- $\gamma$ in MDA-435 cells as well as the ovarian cancer cell lines A2780 and OVCAR5 cells (Fig. 1A). Consistent with a previous study by Jia et al (19), we observed that overexpression of synuclein- $\gamma$ leads to elevated cell motility in MDA-MB-435 cells. Similarly, we observed that synuclein- $\gamma$ overexpression leads to increased cell motility in ovarian cancer cell lines OVCAR5 and A2780 cells (Fig. 1). In Boyden chamber assay, overexpression of synuclein- $\gamma$ enhanced cell motility in A2780 cells by 2- to 3-fold, OVCAR5 cells by 5to 7 fold, and MDA435 cells by 3- to 4-fold (Fig. 1). These data indicate that synuclein- $\gamma$ overexpression can enhance cell motility in both breast and ovarian cancer cells.

We further evaluated whether suppression of synuclein- $\gamma$ has any effect on cell motility. OVCAR5 cells were used for this purpose because of the high endogenous synuclein- $\gamma$ expression in this cell line. We found that cells treated with siRNA showed a significant decrease in the number of migration cells compared to untreated or mock-treated cells (data not shown). These data further support a role for synuclein- $\gamma$ in cell motility.

Activation of the RHO and ERK pathways by synuclein- $\gamma$ overexpression. Among the signaling molecules regulating cell motility, the small GTPases of the RHO family have been shown to play pivotal roles in these signal transduction pathways leading to metastasis (24-26,35). In support of the correlation of synuclein- $\gamma$ with a motile cell phenotype, we found that the GTP-bound active form of at least one member of the RHO family GTPases is elevated in cells that overexpress synuclein- $\gamma$ (Fig. 2). In MDA435/gam cells, activated RHO was increased about 3 -fold by synuclein- $\gamma$. In OVCAR5/ gam cells, RAC and CDC42 were activated by synuclein $-\gamma$, the level of activated RAC or CDC42 was increased approximately 2-fold. Interestingly, RHO, RAC, and CDC42 all showed a 2- to 3-fold increase of the active form in A2780/gam cells, although the fold increase in cell migration in A2780/gam cells was less than that of MDA435/gam and OVCAR5/gam cells. 

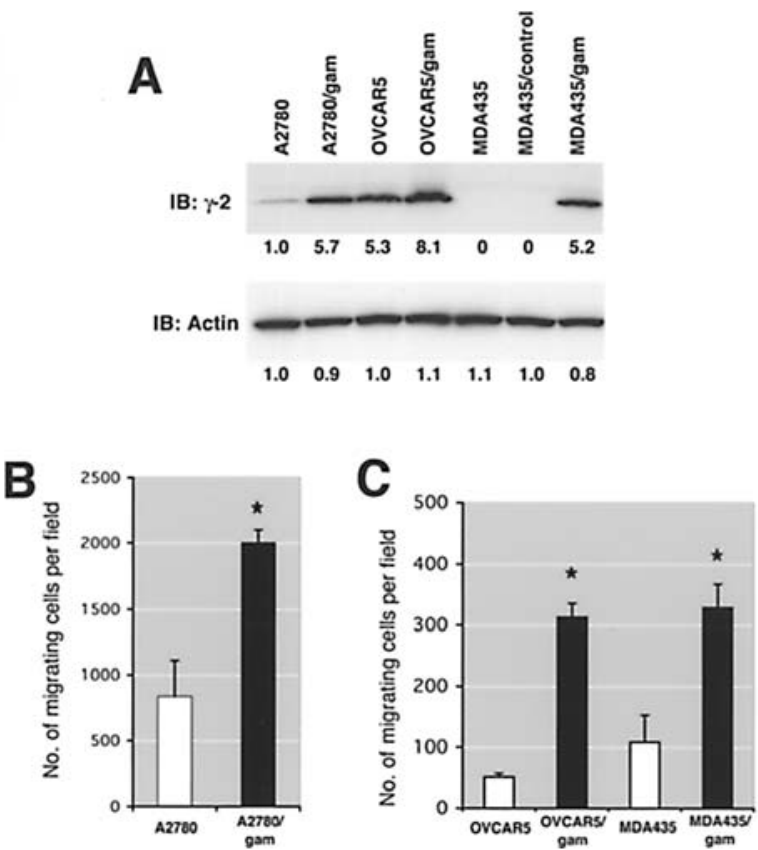

Figure 1. Synuclein- $\gamma$ overexpression can enhance breast and ovarian cancer cell migration. (A) Synuclein $-\gamma$ protein expression levels. Whole cell lysates from the parental cells or stably-transfected cells were analyzed by SDS-PAGE and immuno-blotting. Protein levels of synuclein- $\gamma$ were determined by immuno-blotting (IB) with $\gamma$-2, a polyclonal antibody specific for synuclein- $\gamma$. Protein loading levels were evaluated by immuno-blotting with anti-actin antibody. The numbers beneath each band represent the densitometry units; A2780 was assigned an arbitrary unit of 1.0 for blots with $\gamma-2$ and actin, respectively. Shown here is a representative blot of three independent experiments. (B and C) Boyden chamber assay for cell migration and invasion. In Boyden chamber assay, $3 \times 10^{5}$ cells were plated in the top chamber and cells migrating into the bottom chamber were fixed and stained at $48 \mathrm{~h}$. Cells migrating into the bottom chamber were counted and shown in the graph are the means \pm SEM of migrating cell number per field of triplicate chambers. Shown here is the representative of three independent experiments. *Significant difference $(\mathrm{p}<0.05)$ compared to the parental cells.

The reason we did not observe a more pronounced increase in cell motility in A2780/gam cells is not clear. Synucleins show low homology to 14-3-3 chaperone proteins and have been shown to have chaperone activity as analyzed in vitro $(36,37)$, so we analyzed the protein levels of RHO, RAC, and CDC42 in total cell lysates but none of them was affected by synuclein- $\gamma$ in any of these cell lines. These data indicate that the activation of RHO GTPase family members by synuclein- $\gamma$ is not mediated by affecting the stability of the proteins.

As described previously, several other signaling pathways including ERK have also been identified to promote cell migration and invasion (27-34). In our previous study, we found that ERK is associated with and activated by synuclein- $\gamma$ in A2780/gam and OVCAR5/gam cells (12). Similarly, we found that synuclein- $\gamma$ overexpression led to an approximate 4-fold increase of ERK activation in MDA435/gam cells (Fig. 3). These data suggest that ERK might also be involved in synuclein- $\gamma$ enhanced cell motility.

Both RHO and ERK pathways are required for synuclein- $\gamma$ enhanced cell motility. To determine whether the RHO pathway and ERK pathway are involved in synuclein- $\gamma$-enhanced cell motility, we evaluated the motility of cells treated with C. difficile Toxin $\mathrm{B}$, an inhibitor for all $\mathrm{RHO} / \mathrm{RAC} / \mathrm{CDC} 42$
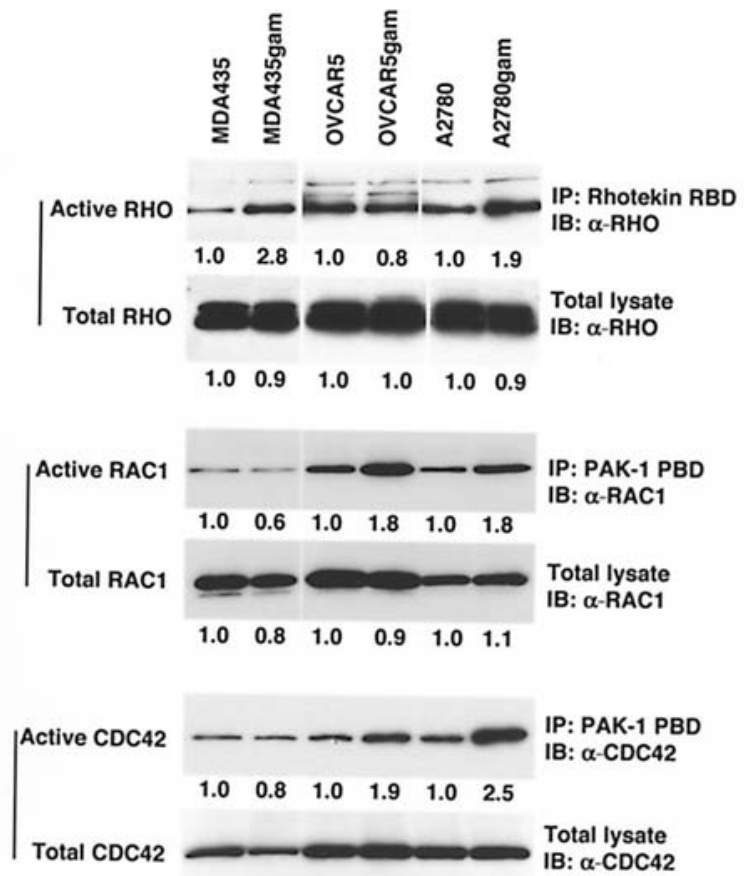

$\begin{array}{llllll}1.0 & 0.7 & 1.0 & 1.1 & 1.0 & 1.1\end{array}$

IB: Actin (Total lysate)

$\begin{array}{llllll}1.0 & 1.0 & 1.0 & 1.0 & 1.0 & 0.9\end{array}$

Figure 2. Activation of RHO family members by synuclein- $\gamma$ overexpression. For RHO activation assay, total cell lysates (1500-2000 $\mu \mathrm{g}$ protein in $1 \mathrm{ml}$ ) from parental cells and their derivative cells that stably overexpress synuclein- $\gamma$ were incubated with $30 \mu \mathrm{g}$ Rhotekin RHO binding domain for $1 \mathrm{~h}$ at $4^{\circ} \mathrm{C}$. Total RHO from $30 \mu \mathrm{g}$ protein of whole cell lysate or the active GTP-bound RHO immunoprecipitated by Rhotekin RBD were detected by SDS-PAGE and immuno-blotting using a polyclonal antibody that recognizes RHO A, B, C. For RAC1 and CDC42 activation assay, total cell lysates $(\sim 1000 \mu \mathrm{g}$ protein in $1 \mathrm{ml})$ from parental cells and their derivative cells that stably overexpress synuclein- $\gamma$ were incubated with 15-20 $\mu$ g PAK-1 PBD agarose for $1 \mathrm{~h}$ at $4^{\circ} \mathrm{C}$. Total RAC1 or CDC42 from $30 \mu \mathrm{g}$ protein of whole cell lysate or the active GTP-bound RAC1 or CDC42 immunoprecipitated by PAK-1 PBD were detected by SDS-PAGE and immuno-blotting using monoclonal antibodies that recognize RAC1 or CDC42, respectively. Protein loading levels were evaluated by immunoblotting with anti-actin antibody. Experiments were performed three times and data from one representative assay are shown. The number beneath each band represents the arbitrary densitometry units of the corresponding band, and each of the parental cell lines (i.e., MDA435, OVCAR5, and A2780, respectively) was assigned an arbitrary unit of 1.0.

members (38), or with the MEK1 inhibitor U0126. The number of migration OVCAR5/gam cells treated with $C$. difficile Toxin B or U0126 was reduced $60-70 \%$ compared to untreated cells. The number of migration OVCAR5 cells treated with C. difficile Toxin B or U0126 was also reduced but to much less extent than OVCAR5/gam cells (Fig. 4A). The number of migration OVCAR5/gam cells treated with either inhibitor is still higher than the untreated parental OVCAR5 cells. In MDA435 and MDA435/gam cells, treatment with either C. difficile Toxin B or U0126 almost completely abrogated cell migration (Fig. 4B). C. difficile Toxin B or U0126 at the dosage used here did not affect cell viability (data not shown). These data further support the hypothesis that synuclein- $\gamma$ enhanced cell motility might be mediated by activation of RHO and ERK pathways. 


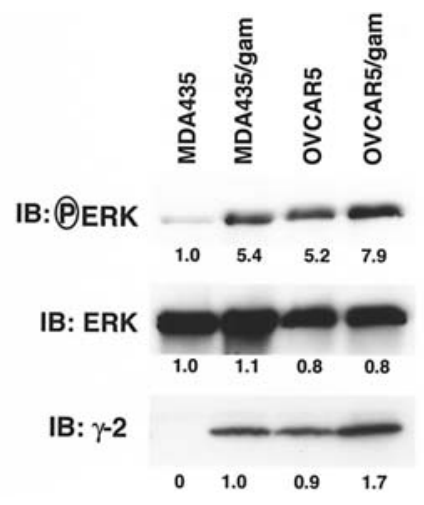

Figure 3. Activation of ERK by synuclein- $\gamma$ overexpression. Total cell lysates from parental cells and their derivative cells that stably overexpress synuclein $-\gamma$ were separated by SDS-PAGE and analyzed by immuno-blotting. Phosphorylated ERK was detected with phospho-ERK specific antibody, and total ERK1/2 was detected with antibodies recognizing total ERK1 and ERK2. The number beneath each band represents the arbitrary densitometry units of the corresponding band; MDA435 was assigned an arbitrary unit of 1.0 for blots with p-ERK and ERK, respectively; and MDA435/gam was assigned an arbitrary unit of 1.0 for blot with $\gamma-2$.
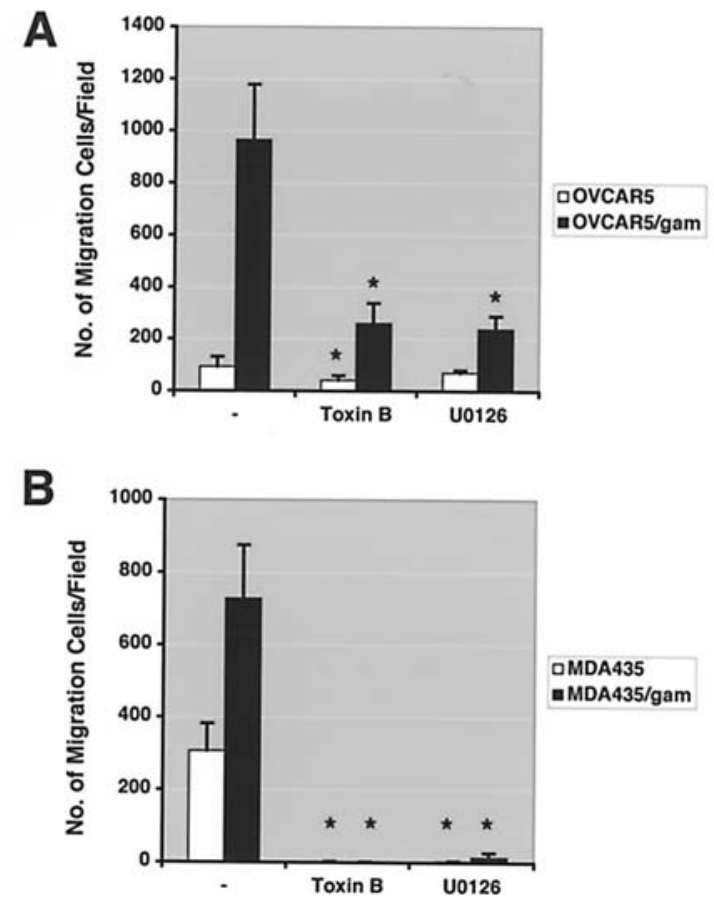

Figure 4. Requirement of RHO family members and ERK in cell migration. Cells $\left(3 \times 10^{5}\right)$ from parental or synuclein $\gamma$ overexpressing cells were plated in the top chamber in $10 \%$ FBS medium for Boyden chamber assay. After allowing cell attachment for $8 \mathrm{~h}$ (A) or $13 \mathrm{~h}$ (B), both the top and bottom chamber were replaced with $10 \%$ FBS medium containing $0.5 \mathrm{ng} / \mathrm{ml}$ C. difficile Toxin B (Sigma-Aldrich, St. Louis, MO), an inhibitor of RHO/RAC/CDC42, or $10 \mu \mathrm{M}$ U0126 (Promega, Madison, WI), an inhibitor of MEK1/2. Cells migrating into the bottom chamber were counted at $66 \mathrm{~h}$ (A) or $52 \mathrm{~h}(\mathrm{~B})$. The graphs represent the means \pm SEM of migrating cell number per field of triplicate chambers. Experiments were repeated three times and data from one representative assay are shown. ${ }^{*}$ Significant difference $(\mathrm{p}<0.05)$ compared to untreated cells.

\section{Discussion}

It has been well established that cancer cells contain many genetic and epigenetic alterations, some are bystander biomarkers, while others could be key etiologic factors contributing to tumor progression and metastasis. Our data in the present study provided further evidence supporting the role of synuclein- $\gamma$ in cell migration and invasion. The mechanism by which synuclein- $\gamma$ enhances cell motility is not clear. MMPs might be one of the mechanisms involved as MMP-2 and -9 are up-regulated by $\gamma$-synuclein in retinoblastoma Y79 cells (20). In MDA-MB-435 cells, however, ectopic overexpression of $\gamma$-synuclein did not activate MMPs (19), suggesting that this mechanism could be cell type dependent. The data in our present study indicated that the small G-protein RHO GTPases and ERK may be involved in synuclein- $\gamma$-enhanced cell motility in breast and ovarian cancer cells.

It remains to be determined how synuclein- $\gamma$ leads to constitutively activated RHO family member(s). The activity of RHO family members is determined by the ratio of GTP/ GDP-bound forms in the cells and the switch of these two forms is regulated by guanosine nucleotide exchange factors (GEFs), GTPase activating proteins (GAPs), and guanosine nucleotide dissociation inhibitors (GDIs) $(39,40)$. One possible mechanism for synuclein- $\gamma$ to activate RHO family members could be by regulating GEFs, GDIs, and GAPs involved in the GTP/GDP exchange, or by regulating signaling event(s) related to GDP/GTP exchange. The RHO family members may regulate different aspects of the cell motility machinery and there are cross-regulations among them depending on the cell type $(39,41-44)$. The activation of RHO family members by synuclein- $\gamma$ could be redundant or contribute to different aspects of cell motility and invasion.

In addition to the RHO pathway, we found that activation of ERK is also involved in synuclein- $\gamma$-enhanced cell motility. We observed in this study that serum is required for synuclein$\gamma$-enhanced cell motility (data not shown), suggesting that ERK inactivation in serum-starved cells could be one of the reasons that cells lose their motile capacity in serum-free medium (12). The inhibitors for RHO family members and ERK inhibit the cell motility of both parental and synuclein- $\gamma$ overexpressing cells, reflecting the fact that these proteins involved in normal cellular processes are not ideal cancer therapy targets. By detailing the mechanism of how RHO family members and ERK are activated by synuclein- $\gamma$, we might be able to abrogate the enhanced activation of these signaling proteins without affecting their normal function.

\section{Acknowledgements}

This work was supported in part by the Lake Champlain Cancer Research Organization (LCCRO), the Eileen Stein-Jacoby Fund, the Department of Defense (DAMD17-01-1-0522, DAMD17-03-1-0115), and NCI Ovarian Cancer SPORE P50 CA83638. We thank Dr Jingwen Liu for providing the MDA-MB-435 cells, and Dr Benoit Giasson for providing the $\gamma-2$ anti-serum.

\section{References}

1. Lavedan C: The synuclein family. Genome Res 8: 871-880, 1998.

2. Surguchov A, Surguchev, I, Solessio E and Baehr W: Synoretin a new protein belonging to the synuclein family. Mol Cell Neurosci 13: 95-103, 1999. 
3. Clayton DF and George JM: Synucleins in synaptic plasticity and neurodegenerative disorders. J Neurosci Res 58: 120-129, 1999.

4. Ji H, Liu YE, Jia T, et al: Identification of a breast cancerspecific gene, BCSG1, by direct differential cDNA sequencing. Cancer Res 57: 759-764, 1997.

5. Bruening W, Giasson BI, Klein-Szanto AJ, Lee VM, Trojanowski JQ and Godwin AK: Synucleins are expressed in the majority of breast and ovarian carcinomas and in preneoplastic lesions of the ovary. Cancer 88: 2154-2163, 2000.

6. Surgucheva I, McMahan B, Ahmed F, Tomarev S, Wax MB and Surguchov A: Synucleins in glaucoma: implication of gamma-synuclein in glaucomatous alterations in the optic nerve. J Neurosci Res 68: 97-106, 2002.

7. Celis A, Rasmussen HH, Celis P, et al: Short-term culturing of low-grade superficial bladder transitional cell carcinomas leads to changes in the expression levels of several proteins involved in key cellular activities. Electrophoresis 20: 355-361, 1999.

8. Sinha P, Hutter G, Kottgen E, Dietel M, Schadendorf D and Lage H: Search for novel proteins involved in the development of chemoresistance in colorectal cancer and fibrosarcoma cells in vitro using two-dimensional electrophoresis, mass spectrometry and microsequencing. Electrophoresis 20: 2961-2969, 1999.

9. Fung KM, Rorke LB, Giasson B, Lee VM and Trojanowski JQ: Expression of alpha-, beta- and gamma-synuclein in glial tumors and medulloblastomas. Acta Neuropathol 106: 167-175, 2003.

10. Liu H, Liu W, Wu Y, et al: Loss of epigenetic control of synuclein-gamma gene as a molecular indicator of metastasis in a wide range of human cancers. Cancer Res 65: 7635-7643, 2005.

11. Gupta A, Godwin AK, Vanderveer L, Lu A and Liu J: Hypomethylation of the synuclein gamma gene $\mathrm{CpG}$ island promotes its aberrant expression in breast carcinoma and ovarian carcinoma. Cancer Res 63: 664-673, 2003.

12. Pan ZZ, Bruening W, Giasson BI, Lee VM and Godwin AK: Gamma-synuclein promotes cancer cell survival and inhibits stress- and chemotherapy drug-induced apoptosis by modulating MAPK pathways. J Biol Chem 277: 35050-35060, 2002.

13. Gupta A, Inaba S, Wong OK, Fang G and Liu J: Breast cancerspecific gene 1 interacts with the mitotic checkpoint kinase BubR1. Oncogene 22: 7593-7599, 2003.

14. Liu J, Spence MJ, Zhang YL, Jiang Y, Liu YE and Shi YE: Transcriptional suppression of synuclein gamma (SNCG) expression in human breast cancer cells by the growth inhibitory cytokine oncostatin M. Breast Cancer Res Treat 62: 99-107, 2000.

15. Lu A, Zhang F, Gupta A and Liu J: Blockade of AP1 transactivation abrogates the abnormal expression of breast cancer-specific gene 1 in breast cancer cells. J Biol Chem 277: 31364-31372, 2002.

16. Inaba S, Li C, Shi YE, Song DQ, Jiang JD and Liu J: Synuclein gamma inhibits the mitotic checkpoint function and promotes chromosomal instability of breast cancer cells. Breast Cancer Res Treat 94: 25-35, 2005.

17. Jiang Y, Liu YE, Goldberg ID and Shi YE: Gamma synuclein, a novel heat-shock protein-associated chaperone, stimulates ligand-dependent estrogen receptor alpha signaling and mammary tumorigenesis. Cancer Res 64: 4539-4546, 2004.

18. Jiang Y, Liu YE, Lu A, et al: Stimulation of estrogen receptor signaling by gamma synuclein. Cancer Res 63: 3899-3903, 2003.

19. Jia T, Liu YE, Liu J and Shi YE: Stimulation of breast cancer invasion and metastasis by synuclein gamma. Cancer Res 59: 742-747, 1999.

20. Surgucheva IG, Sivak JM, Fini ME, Palazzo RE and Surguchov AP: Effect of gamma-synuclein overexpression on matrix metalloproteinases in retinoblastoma Y79 cells. Arch Biochem Biophys 410: 167-176, 2003.

21. Orr FW and Wang HH: Tumor cell interactions with the microvasculature: a rate-limiting step in metastasis. Surg Oncol Clin North Am 10: 357-381, 2001.
22. Orr FW, Wang HH, Lafrenie RM, Scherbarth S and Nance DM: Interactions between cancer cells and the endothelium in metastasis. J Pathol 190: 310-329, 2000.

23. Turley EA: Molecular mechanisms of cell motility. Cancer Metastasis Rev 11: 1-3, 1992.

24. Etienne-Manneville S and Hall A: Rho GTPases in cell biology. Nature 420: 629-635, 2002.

25. Clark EA, Golub TR, Lander ES and Hynes RO: Genomic analysis of metastasis reveals an essential role for RhoC. Nature 406: 532-535, 2000.

26. Ridley AJ: Rho GTPases and cell migration. J Cell Sci 114: 2713-2722, 2001

27. Klemke RL, Cai S, Giannini AL, Gallagher PJ, De Lanerolle P and Cheresh DA: Regulation of cell motility by mitogenactivated protein kinase. J Cell Biol 137: 481-492, 1997.

28. Krueger JS, Keshamouni VG, Atanaskova N and Reddy KB: Temporal and quantitative regulation of mitogen-activated protein kinase (MAPK) modulates cell motility and invasion. Oncogene 20: 4209-4218, 2001.

29. Cho SY and Klemke RL: Extracellular-regulated kinase activation and CAS/Crk coupling regulate cell migration and suppress apoptosis during invasion of the extracellular matrix. J Cell Biol 149: 223-236, 2000.

30. Anand-Apte B, Zetter BR, Viswanathan A, et al: Plateletderived growth factor and fibronectin-stimulated migration are differentially regulated by the Rac and extracellular signalregulated kinase pathways. J Biol Chem 272: 30688-30692, 1997.

31. Delehedde M, Sergeant N, Lyon M, Rudland PS and Fernig DG: Hepatocyte growth factor/scatter factor stimulates migration of rat mammary fibroblasts through both mitogen-activated protein kinase and phosphatidylinositol 3-kinase/Akt pathways. Eur J Biochem 268: 4423-4429, 2001.

32. Ellerbroek SM, Halbleib JM, Benavidez M, et al: Phosphatidylinositol 3-kinase activity in epidermal growth factor-stimulated matrix metalloproteinase- 9 production and cell surface association. Cancer Res 61: 1855-1861, 2001.

33. Wicki A and Niggli V: The Rho/Rho-kinase and the phosphatidylinositol 3-kinase pathways are essential for spontaneous locomotion of Walker 256 carcinosarcoma cells. Int J Cancer 91: 763-771, 2001.

34. Chiarugi P, Cirri P, Taddei L, et al: The low M(r) proteintyrosine phosphatase is involved in Rho-mediated cytoskeleton rearrangement after integrin and platelet-derived growth factor stimulation. J Biol Chem 275: 4640-4646, 2000.

35. Ridley AJ: Rho family proteins: coordinating cell responses. Trends Cell Biol 11: 471-477, 2001.

36. Ostrerova N, Petrucelli L, Farrer M, et al: alpha-Synuclein shares physical and functional homology with $14-3-3$ proteins. J Neurosci 19: 5782-5791, 1999.

37. Souza JM, Giasson BI, Lee VM and Ischiropoulos H: Chaperonelike activity of synucleins. FEBS Lett 474: 116-119, 2000.

38. Bishop AL and Hall A: Rho GTPases and their effector proteins. Biochem J 348: 241-255, 2000.

39. Van Aelst L and D'Souza-Schorey C: Rho GTPases and signaling networks. Genes Dev 11: 2295-2322, 1997.

40. Takai Y, Sasaki T and Matozaki T: Small GTP-binding proteins. Physiol Rev 81: 153-208, 2001.

41. Guasch RM, Scambler P, Jones GE and Ridley AJ: RhoE regulates actin cytoskeleton organization and cell migration. Mol Cell Biol 18: 4761-4771, 1998.

42. Banyard J, Anand-Apte B, Symons M and Zetter BR: Motility and invasion are differentially modulated by Rho family GTPases. Oncogene 19: 580-591, 2000.

43. Sander EE, ten Klooster JP, van Delft S, van der Kammen RA and Collard JG: Rac downregulates Rho activity: reciprocal balance between both GTPases determines cellular morphology and migratory behavior. J Cell Biol 147: 1009-1022, 1999.

44. Spaargaren M and Bos JL: Rab5 induces Rac-independent lamellipodia formation and cell migration. Mol Biol Cell 10: 3239-3250, 1999. 